\title{
The Social Philosophical Dimensions of Hospice Care
}

\author{
Jason L. Powell \\ Chester University, United Kingdom \\ E-mail address: jasonpwll3@gmail.com
}

Keywords: hospice; philosophy; end of life; death and institutionalisation

\begin{abstract}
Hospice care is a type of care and philosophy of care that focuses on the palliation of a terminally ill or seriously ill patient's pain and symptoms, and attending to their emotional and spiritual needs (Powell 2014). The concept of hospice has been evolving since the 11th century. Then, and for centuries thereafter, hospices were places of hospitality for the sick, wounded, or dying, as well as those for travellers and pilgrims (Dossey 1999). The modern concept of hospice includes palliative care for the incurably ill given in such institutions as hospitals or nursing homes, but also care provided to those who would rather spend their last months and days of life in their own homes (McCue and Thompson 2006).
\end{abstract}

\section{INTRODUCTION}

The concept "hospice" derives from the Latin hospes, a word which served double duty in referring both to guests and hosts. Historians believe the first hospices originated in the 11th century, around 1065. The rise of the Crusading movement in the 1090s saw the incurably ill permitted into places dedicated to treatment by Crusaders. The history of the hospice began to emerge in the $17^{\text {th }}$ century, but many of the foundational principles by which modern hospice services operate were pioneered in the 1950s by Dame Cicely Saunders in the United Kingdom (Powell 2014). Hospice is a concept of caring borrowed from medieval times, where travelers, pilgrims and the sick, wounded or dying could find rest and comfort. The contemporary hospice offers a program of care to patients and families facing a life threatening illness encompassing medical, nursing, spiritual, and psychological care. It is more than a medical alternative - it is an attitude toward death and the process of dying. Terminal disease is managed so that patients can live comfortably until they die. The hospice program in the United States has evolved in part as an attempt to compensate for the inadequacies of the present medical system, particularly in caring for patients with a terminal illness. Hospice care has grown from an alternative health care movement to an established component of the American health care system. Yet there has been little work to date reviewing the literature or consulting with experts in hospice care in a more systematic way to establish what contributes to the quality of hospice care. This is important to do for a number of reasons. It is vital in defining relevant outcomes for hospice care, in shaping the skill base of the future hospice workforce and in confirming how hospice care can contribute to the wellbeing of individuals and communities, and to the effectiveness of health and social care systems. These are important considerations for hospices as they plan to position themselves in the future, as described by the Commission into the Future of Hospice Care.

Within the US, the concept is largely defined by the practices of the Medicare system and other health insurance providers, which make hospice care available, either in an inpatient facility or at the patient's home, to patients with a terminal prognosis who are medically certified to have less than six months to live (Powell 2014). One solution to end-of-life care, the hospice movement, has seen incredible growth in the United States over the past several decades. It has been over 40 years since hospice care began in the United States. Today, hospice focuses on, "caring, not curing and, in most cases: care is provided in a patient's home. Care can also be provided in freestanding hospice centers, hospitals, and nursing homes or other long-term care facilities (McCue and Thompson 2006). Hospice services, which include care management for all aspects of the patient, 
include family support as well (Levine 1997). Hospices offer wide-ranging, personalised care which is provided by a versatile team of different professional staff and volunteers. As well as taking care of people's physical needs, they also look after their emotional, spiritual and social needs. They also support carers, family members and close friends, both during a person's illness and during bereavement.

Outside the United States, the term hospice tends to be primarily associated with the particular buildings or institutions that specialize in such care (although so-called "hospice at home" services may also be available). In Europe, such institutions may similarly mostly provide care in an end-oflife setting, but they may also be available for patients with other specific palliative care needs (Levine 1997). Hospice care also involves assistance for patients' families to help them cope with what is happening and provide care and support to keep the patient at home. Although the movement has met with some resistance, hospice has rapidly expanded through the United Kingdom, the United States and elsewhere (Schwartz, 2002). In essence, Hospice is designed to help those who are in their last months of life and is most effective when used in this way. However, hospice care may be used during a person's final few days or for more than 6 months if recommended by the person's physician. Most hospice patients are older, but hospice care can be helpful for persons of any age, including children, if their life-ending illness is in its last stages. Many persons with advanced cancers, Alzheimer disease, amyotrophic lateral sclerosis, AIDS, and severe chronic kidney disease receive hospice care during the final phase of their diseases.

The number of hospice programs in the United States has grown steadily since 1974, increasing to more than 4,500 programs in 2006. The greatest growth has been in the number of forprofit hospices. Over the past decade, the number of for-profit hospices has increased nearly fourfold (McCue and Thompson 2006). Between 2001 and 2003 alone, the number of for-profit hospices increased $25 \%$, compared with an overall $8 \%$ increase in hospice programs. One study found that $91 \%$ of 44 new, freestanding hospices that opened between 2002 and 2003 were owned by for-profit organizations. As a result, for-profit hospices now account for $46 \%$ of the total number of programs (McCue and Thompson 2006).

The use of hospice in the United States has also increased. According to the National Hospice and Palliative Care Organization, the number of people using hospice increased from 495,000 in 1997 to 1.3 million in 2006, an increase of 162\% during 10 years (National Hospice and Palliative Care Organization 2007). Patients with cancer once comprised the majority of patients receiving hospice care and while it remains the top diagnosis among hospice enrolments, its percentage is decreasing. In 2006, cancer accounted for approximately $44 \%$ of the diagnoses (National Hospice and Palliative Care Organization 2007). The steady decrease in cancer diagnoses reflects lower cancer-related mortality rates as well as an increased awareness about hospice among people with other chronic conditions. The decrease may also represent an increasing tendency of individuals with cancer to choose potentially curative treatments rather than hospice (National Hospice and Palliative Care Organization 2007).

Treatments given with potentially curative intent are not allowable under the Medicare Hospice Benefit (MHB), the primary payer for hospice care in the United States. The MHB was enacted by the US Congress in 1982, and nearly 93\% of US hospices are now certified by the Centers for Medicare and Medicaid Services to file for reimbursement under this benefit. Spending on hospice through MHB has increased from \$1.9 billion in 1995 to $\$ 8.1$ billion in 2005 (National Hospice and Palliative Care Organization, 2007).

Palliative care is defined by the World Health Organization (WHO) as an approach that improves quality of life for patients and their families facing the problems associated with lifethreatening illness, through the prevention and relief of suffering by means of early identification 
and impeccable assessment and treatment of problems, including physical, psychosocial, and spiritual (National Hospice and Palliative Care Organization, 2007).

There is a growing understanding of hospice and palliative care among most people in society, as the realization that hospice is not a place but rather a concept gains momentum, and patients opt for palliative care services earlier in their illness. We must not fail to acknowledge the great work accomplished by hospice and palliative care professionals. This effort must continue to expand in order to reduce access disparities across the nation. The challenge for hospice and palliative care providers can be boiled down to achieving unfettered access to quality palliative care for all who need it (National Hospice and Palliative Care Organization, 2007).

While use and advantages of palliative care and hospice are gaining momentum at unprecedented pace, there remains disparity in access geographically. In addition to general access disparities, the type of care patients receive at the end of their life varies according to where they live and what acute care facility they happen to be a patient in. In 2001, Moody and Arcangel discussed the likelihood of dying in a hospice in the United States as depending on, not patient preference, but rather on number of hospital beds, and physician per patient statistics, which varied greatly across the nation. Medicare beneficiaries in some western and northwestern states had a less than a $20 \%$ chance of dying in a hospital, while chances for those in southern and eastern states could be greater than 50\% (Moody and Arcangel 2001).

Research supports the fact this issue is still apparent; geography continues to play a role in end-of-life care today. Powell (2014) points out that for patients with advanced cancer, the likelihood they will spend their last days in a hospital intensive care unit depends largely on where they live, and which hospital they seek care in.

Not only is there disparity in whether patients go to and utilize acute care services, but also, once there, there is disparity in what types of care they receive in those acute care organizations. Extensive variation was found in length of stay, number of physician visits, percentage of patients with 10 or more physicians, and transfers to hospice services (Schwartz, 2002).

Medicare, the largest health plan in the United States, is highly influential in end-of-life care because of the large number of beneficiaries who die each year. Numbers vary depending on the source, but according to the Medicare Payment Advisory Com - mission (MedPAC), about a quarter of the total Medicare budget is spent on services for beneficiaries in their last year of life, and $40 \%$ of that is in the last 30 days of their life (Powell 2014).

Chronic disease is an important item to review when discussing end-of-life care, because hospice patients are no longer predominately cancer patients, but also now have diagnoses that include multiple chronic conditions. According to the National Health Statistics Report, in recent years, hospice has become increasingly used by people with noncancerous diagnosis, the rate of which has increased from $25.3 \%$ in 2000 to $57.2 \%$ in 2005 (McCue and Thompson, 2006). Another factor that cannot be overlooked is that many of these future older Americans will originate from ethnic and racial minority groups; therefore, end-of-life care and reform efforts must include an assessment and understanding of the care needs for these culturally diverse groups. Since a large payer of hospice services is Medicare, there is no doubt that political debate exists when discussions about payment for this care are undertaken. However, one thing is certain, discussions regarding quality of care, health policy, and disparity must begin to occur and cannot be dismissed due to the fact these conversations are difficult to have from an ethical and legal perspective. Components of these conversations must include the cost of end-of-life care in acute settings and possible hospice and palliative care contributions as solutions to decrease those costs (Powell 2014).

Additional problems exist related to ill-defined quality standards, and decreased numbers of professionals working in hospice or palliative care across geographical pockets, especially in rural areas of the United States (Carlson, Morrison and Holford 2007). End-of-life care issues remain unsolved as a result of an inability of a nation and its people, including political leaders, to discuss what is inevitable for all - mortality. End-of- life ethical and political policy conversations are difficult and, at times, avoided. There is unwillingness or uneasiness at best, to approach this subject head on (Powell 2014). 
Multiple studies discuss educational deficiencies and lack of comfort levels that nurses have when it comes to conducting follow up or clarification discussions with patients about end-of-life care or treatment options (Powell 2014). Changes in nursing education must occur in order to prepare professional nurses to become advocates and experts in end-of-life care. When assessing the adequacy of skill of health care professionals to initiate and conduct end-of-life conversations there are noted voids and problems.

Carlson, Morrison and Holford (2007) identified several skill sets that nurses felt were important but underutilized in end-of-life care conversations. They concluded end-of-life care interventions should address not only system and policy changes, but also improvements in individual nurse's communication skills regarding end-of-life conversations (Carlson, Morrison and Holford 2007). Nurses can play a pivotal role in patient and family illness and care awareness by facilitating palliative care communication and supporting the conceptual shift to early palliative care (Carlson, Morrison and Holford 2007). The communication problem exists for physicians as well. Part of this problem originates from poor preparation of professionals in their primary and early health care education programs. While many programs are adapting methods to include didactic training programs, the real experience comes from actual conversations, which of course, is not something a text or video can accomplish. Programs like the End of Life Nursing Education Consortium and continued efforts in physician mentoring and role modelling in end-of-life care conversations will prove very beneficial (Powell 2014).

The development and spread of palliative care efforts and hospice education for professionals and the general public will continue to have an impact on growth and acceptance of end-of-life conversations. It is also important for individual professionals, as well as the organizations they work within, to continue to foster and participate in opportunities and experiences that will enhance ability and comfort levels regarding end-of-life conversations. This effort will be of utmost importance for not only physicians, but also for nurses (Carlson, Morrison and Holford 2007).

Elements of hospice care

Pain management: Treating pain as part of hospice may include medications and doses with adverse effects that might not normally be acceptable for a person who is not dying. A physician specializing in the treatment of chronic pain may be involved in the care.

Involving family: Family caregivers may provide support, comfort, and help with the patient's activities of daily living. Family presence during the dying process can benefit the patient and the family members. Hospice workers help family and caregivers understand what happens to people when they are dying.

A multidisciplinary, team-focused approach: Members of the hospice team may include a physician with specialized education in palliative medicine (relieving discomfort when illness is not curable), nurses with education in caring for dying patients, social workers, therapists, chaplains and other spiritual leaders, specially trained aides, and volunteers. Hospice professionals offer support, guidance, and resources for family members before and after a patient's death.

Communication is the cornerstone of basic nursing practice and a fundamental skill across all settings of care is to identify the patient's goals of care. As patients and families continue to face serious illness, transition to palliative care, and make difficult decisions, nurses will play a critical role and remain as the predominant professional at the bedside (Powell 2014). Physicians most often will champion the initial conversation with patients and families, but nurses have a responsibility and professional ethic to be present for the patient and family after initial conversations takes place. Nurses accompany patients on their journeys; through such ongoing and intimate encounters, they support patients in confronting the weariness of living and dying (Aitken 1985). Health care professionals, including nurses, must be vigilant about understanding their communication style and engaging in educational opportunities that enhance their ability to conduct effective end-of-life conversations with patients and families (Kircher 1995).

Hospice and palliative care professionals must ensure their voice is heard when it comes to creation of policy. Local, state, and grassroots end-of-life programs should continue to be 
developed, financed, and evaluated. While some financing may come from grants or private sources, states should actively assess what they can do to assist financing any initiative that promotes or enhances end-of-life care.

\section{BIOGRAPHY}

Jason L. Powell BA (Hons), MA, Ph.D, FRSA is teaches on the criminology programme at University of Chester. He is formerly Professor of Social Gerontology and Associate Dean of Faculty of Health and Life Sciences at University of Coventry. He holds an Honorary Fellowship at University of Liverpool; Honorary Professor at Australia-Asia Research and Education Foundation at Tasmania University; Visiting Research Fellow at Oxford; and recently invited as Visiting Scholar at Harvard University. He has been Visiting Professor in Canada, US, Australia, Africa and Jordan. He was nominated and elected to Fellowship of the British Royal Society of Arts (FRSA) in recognition of his research. He has strong interests in social theory, ageing, power and identity. He is author of Social Theory and Ageing (2006) which was part of Charles Lemert's distinguished 'New Social Formations' book series, Rowman and Littlefield: New York.

\section{References}

[1] Aiken, Lewis R. (1985). Dying, Death, and Bereavement. Allyn and Bacon.

[2] Carlson MD, Morrison RS, Holford TR (2007) 'Hospice care: What services do patients and their families receive?’ Health Services Research 42:1672-1690

[3] Dossey, L. (1999) Reinventing Medicine: Beyond the Mind-Body to a New Era of Healing. Harper: San Francisco

[4] Kircher, P (1995) Love is the Link: A Hospice Doctor Shares Her Experience of Near-Death and Dying. Larson Publications: New York

[5] Levine, S (1997) One Year to Live: How to Live This Year as If It Were Your Last. Bell Tower: New York

[6] McCue MJ, and Thompson J (2006) 'Operational and financial performance of newly established hospices’. American Journal Hospital Palitative Care 23:259-266.

[7] Moody, R and D Arcangel (2001) Life after Loss: Conquering Grief and Finding Hope. San Francisco: Harper Collins

[8] National Hospice and Palliative Care Organization (2007) NHPCO Facts and Figures: Hospice Care in America (National Hospice and Palliative Care Organization, Alexandria, VA).

[9] Powell, J.L (2014) Social Gerontology Nova Science: New York

[10] Schwartz, G (2002). The Afterlife Experiments: Breakthrough Scientific Evidence of Life after Death. New York: Simon and Schuster 